\title{
Nova Scotia targets orthopedic wait times
}

$\mathrm{D}$ r. Eric Howatt describes his office as the "the crying clinic." The orthopedic surgeon and chief of surgery at Valley Regional Hospital in Kentville, Nova Scotia, has the onerous task of explaining to patients why their wait times for hip or knee replacements are routinely three times the national benchmark: 18 months instead of 6 .

"They need the operation as soon as we can make them ready," says Howatt. "So when you sit in front of them and tell them it's going to be two years ... they're upset and their families are upset."

"It's not safe," he adds. "Their entire health suffers."

As co-chair of a provincial government orthopedic working group, it's a situation Howatt is hoping to remedy.

A 2014 report from the province's auditor general, Michael Pickup, documented long wait times across specialties, but the longest waits are for orthopedic surgery. The average wait for knee replacement surgery in 2013 was 615 days; the benchmark is 180 days. The report further noted that approximately $\$ 35$ million would be needed to begin completing $90 \%$ of hip and knee replacements within the six-month benchmark.

Nova Scotia Minister of Health and Wellness Leo Glavine says his government is trying to trim the orthopedic wait times. An additional $\$ 4.2$ million was put into last year's budget for orthopedic surgeries; that funding will continue in this fiscal year. But it is still a far cry from the $\$ 35$ million the auditor general says is needed.

About 3300 patients require joint replacements annually in Nova Scotia, but only about 2300 are typically performed, says Howatt. The additional $\$ 4.2$ million funded an additional 400 joint surgeries last year, bringing the

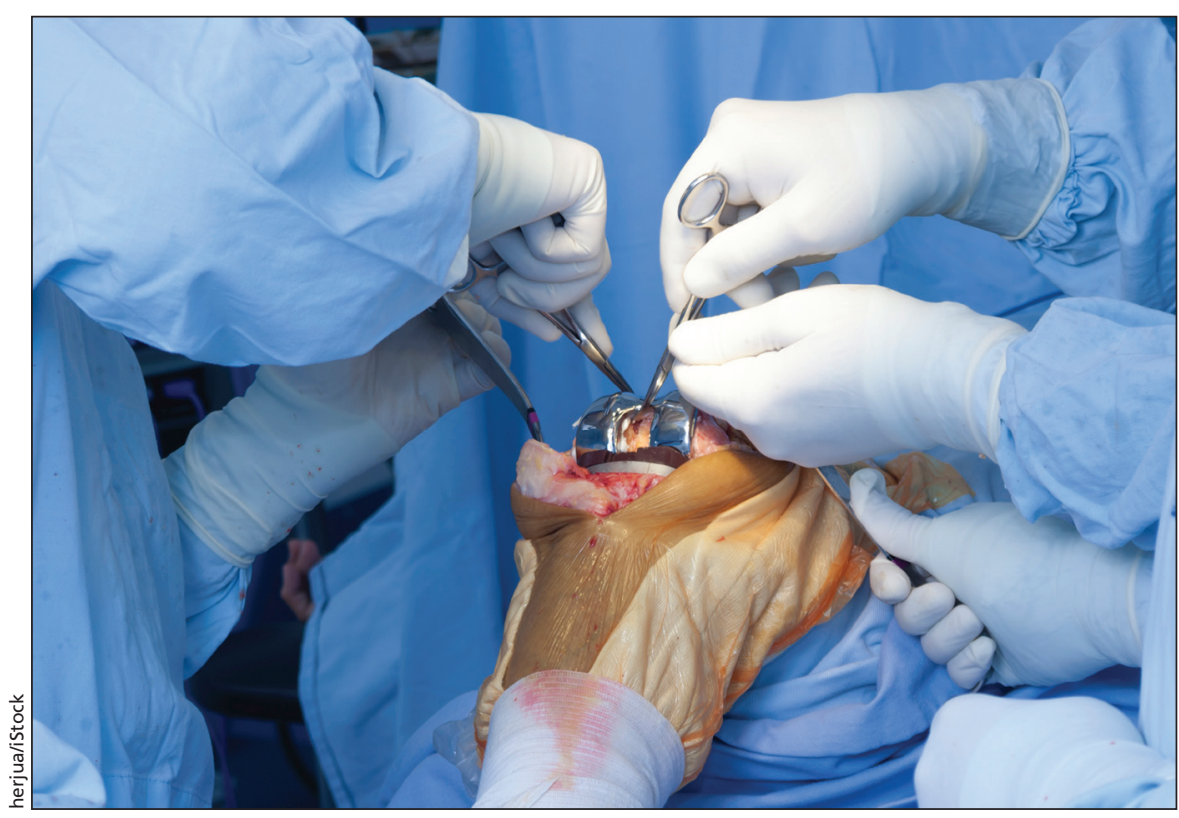

Waits for knee and hip replacements in Nova Scotia are routinely three times the national benchmark.

total to 2700 . The goal is to meet yearly demand and perform extra joint replacement procedures. Ideally, eliminating this backlog would mean a reduction in wait time to the standard six months. This would mean surgeons would perform about 1600 surgeries annually.

"With additional resources and better management of existing resources, this could happen over the next three to four years," Howatt says. "It's not going to be easy, but it's conceivable." The problem is longstanding. "Successive governments, despite this being pointed out to them, didn't act."

The causes are multifactorial. There are a sufficient number of orthopedic surgeons in Nova Scotia, but there are often shortages of the support staff required for joint replacement surgery. Christmas and summer slowdowns, as well as elective-surgery cancellations triggered by strikes, are also to blame.
And there are bed shortages. "In my hospital, we've had close to 40 joint surgeries cancelled over the past five months because of bed shortages," says Howatt.

Formed in 2012, the orthopedic working group is taking a province-wide approach, advising the government on how to better distribute resources among orthopedic surgery sites. The group doesn't set budgets, "but hopefully we can set agendas," Howatt says.

Glavine says the working group has the potential to be a "model for the province."

Howatt is encouraged. "The government has listened to us ... We are getting somewhere. It's just slow," he says. "For those people that are unfortunately on the waiting list at this time, it probably seems incredibly slow." - Quentin Casey, Mahone Bay, Nova Scotia

CMAJ 2015. DOI:10.1503/cmaj.109-5073 